\title{
Radiation Exposure in the United States
}

\author{
By DADE W. MOELleR, M.S., JAMES G. TERRILL, JR., C.E., M.B., \\ and SAMUEL C. INGRAHAM, II, M.D., M.P.H.
}

$\mathrm{T}$ HE HUMAN RACE has always been exposed to some ionizing radiation of cosmic origin and from natural sources in the environment and within the body. During a lifetime, a person who lives to be 70 years of age is exposed, on the average, to about 9 roentgens of radiation from these sources. Today, however, radiation from these sources comprises only a small portion of the total exposure received by man. Radiation-generating machines and radioactive materials, which are being employed in nearly all phases of the environment, constitute the principal sources of radiation.

Knowledge of the wide variety of sources and of the levels of radiation exposure is essential to the planning and conducting of a sound radiological public health program. Data available in the literature on the extent of radiation exposures in the United States are reviewed here to aid the many State and local health departments engaged in determining and evaluating radiation sources affecting public health in their areas. Neither the control of radiation exposure nor specific public health effects of the exposure are discussed in this paper.

Mr. Moeller, a sanitary engineer, is an environmental radiation specialist with the radiological health branch, Division of Engineering Resources, Bureau of State Services, Public Health Service. Mr. Terrill is acting chief of the branch and chairman of the Committee on Radiological Health of the Engineering Section, American Public Health Association. Dr. Ingraham is assistant chief of the branch.

\section{Medical and Dental Uses of X-ray}

In the United States today, more than 125,000 $\mathrm{X}$-ray units are being used for diagnosis and therapy-approximately 50,000 by general practitioners, physician specialists, radiologists, and in hospitals and clinics $(1) ; 65,000$ by dentists; and 11,000 by doctors of osteopathy and doctors of chiropractic.

In the operation of these X-ray units, more than 215,000 medical-technical personnel are potentially exposed to radiation. These personnel include about 3,000 radiologists devoting full time to their specialty, 500 physicians devoting most of their time to radiology, 600 physicians who are second- and third-year residents in radiology, 31,000 general practitioners and specialists owning their own equipment (1), 67,000 dentists, 11,000 osteopaths and chiropractors, 40,000 X-ray technicians, and probably close to 40,000 dental technicians and assistants. This listing undoubtedly omits many nurses, clerks, attendants, and technicians who are exposed to radiation in a lesser degree.

Although many instances of excessive exposure of X-ray personnel are reported in the literature, few specific data are available regarding average exposure for these workers. In a 3-week survey of personnel in doctors' and dentists' offices and X-ray departments, it was found that about 3 percent of the exposures exceeded the present-day maximum permissible dose of 0.3 roentgen per week. However, 81.5 percent were less than 0.05 roentgen per week (2). In a 9-month survey of personnel in $\mathrm{X}$-ray departments only, about 0.4 percent of the exposures exceeded 0.3 roentgen per week, 


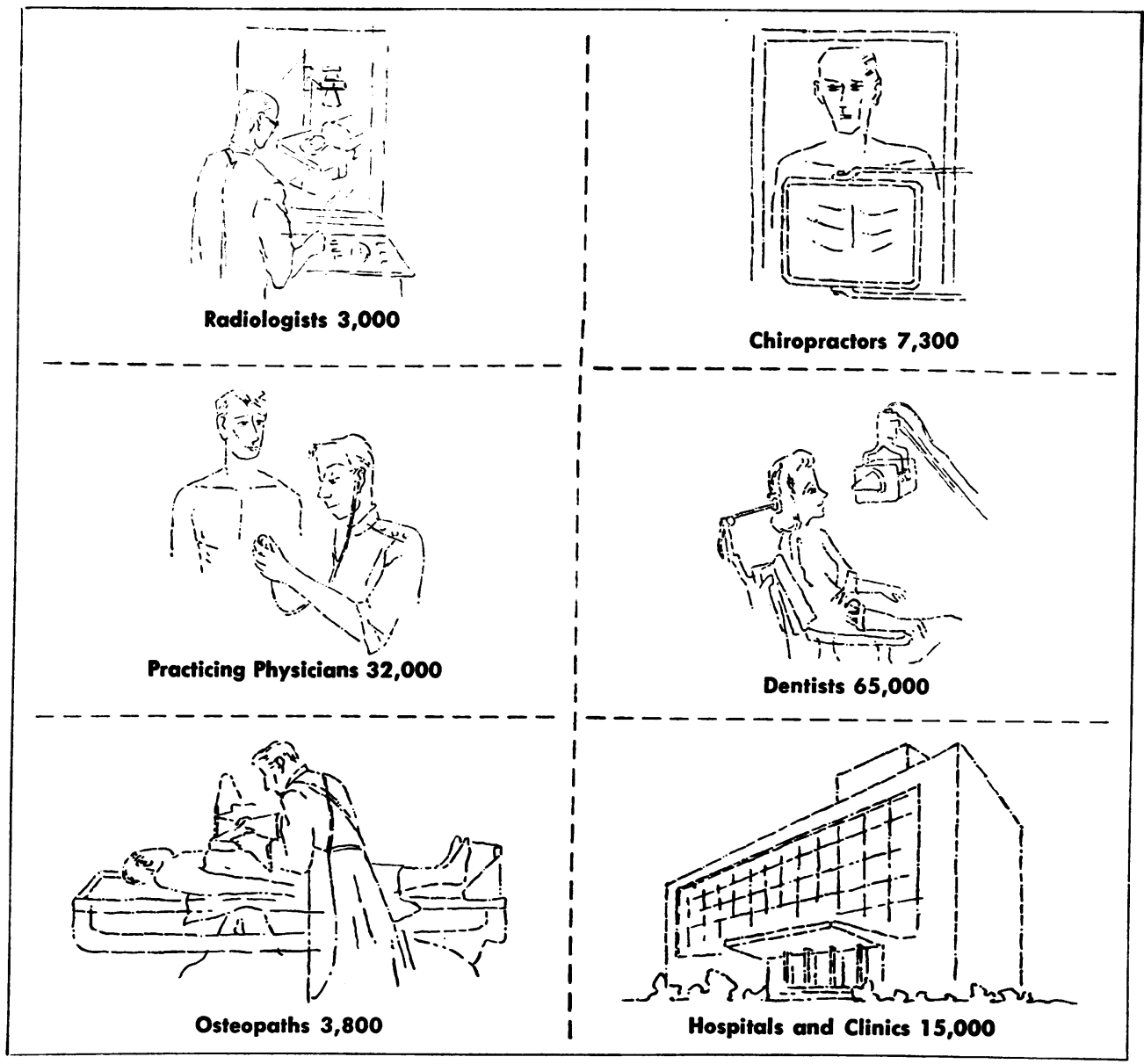

$X$-ray units in the healing arts

with 97 percent being less than 0.05 roentgen per week (2).

Exposures of X-ray personnel in Public Health Service hospitals range from 0 to 0.46 roentgen per 2-week period. An appreciable fraction of radiologists experience exposures averaging more than 0.1 roentgen per day. About 20 percent of the personnel operating photofluorographic equipment exceeded 0.3 roentgen per week prior to the start of a successful radiation control program.

Operators of dental $\mathrm{X}$-ray machines receive approximately 0.1 roentgen of general body exposure per eight mouth examinations, each of which consists of ten 3 -second exposures. This figure assumes careful operation of the unit. In conducting mass dental $\mathrm{X}$-ray surveys, operators can easily receive the maximum permissible dose of radiation even with some rotation of operators. Persons in the immedi- ate area of dental $\mathrm{X}$-ray units can receive appreciable percentages of the maximum permissible dose.

In addition to the operators, a considerable portion of the general population is also exposed to radiations from $\mathrm{X}$-ray machines. Of the $2,500,000$ persons seen daily by physicians, a large number have some $\mathrm{X}$-ray diagnostic procedure performed upon them by the physicians, and 82,000 are referred to radiologists. Approximately 25,000,000 X-ray examinations are given annually by radiologists (1). Data relative to radiation exposures resulting from these examinations are summarized below :

\begin{tabular}{|c|c|c|}
\hline Type of examination & $\begin{array}{l}\text { Average radia- } \\
\text { tion dosage } \\
\text { (roentgens) }\end{array}$ & $\begin{array}{c}\text { Distribution } \\
\text { (percent) }\end{array}$ \\
\hline $\begin{array}{l}\text { Radiographic } \\
\text { Photofluorographic } \\
\text { Fluoroscopic }\end{array}$ & $\begin{array}{lr}- & 2.7 \\
- & 1.0 \\
- & 65.0\end{array}$ & $\begin{array}{l}51.88 \\
\text { 33. } 64 \\
14.48\end{array}$ \\
\hline
\end{tabular}




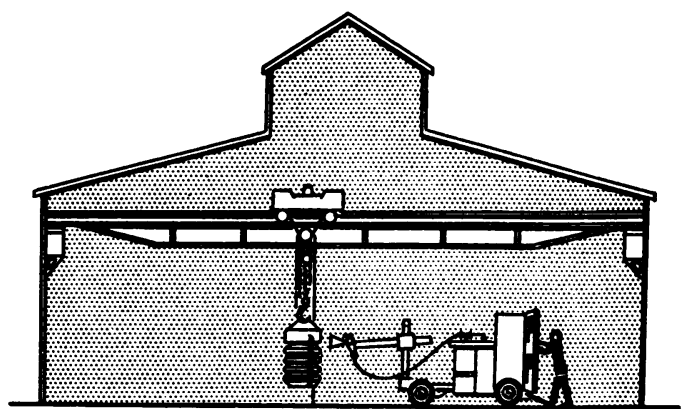

Industrial X-ray installation

The radiation exposures range from approximately 1 roentgen for a photofluorographic examination to about 65 roentgens for an average fluoroscopic examination. Using the data in the above table and weighting each radiation dosage by its percentage distribution, an overall average radiation dose can be calculated. This average dose is 11 roentgens per examination.

$\mathrm{X}$-ray treatments given annually by radiologists number more than $4,000,000$ (1). These treatments are usually confined to a very small portion of the patient's body, and are usually administered at several sittings. The average total dosage per patient is about 5,000 to 7,000 roentgens.

Probably the largest single source of medical radiation exposure in the United States is the mass chest X-ray survey for tuberculosis. An estimated 15,000,000 persons were given chest $X$-rays in such surveys in 1950. Most of the $\mathrm{X}$-rays given in the mass survey are the photofluorographic type, which results in about 1.0 roentgen exposure to the patient's chest per examination.

Some $84,000,000$ films are used annually for dental X-ray examinations. In 1949, the 60 million persons ( 40 percent of the population) who visited their dentists were potentially exposed to radiation from this source. The average exposure to the patient per film is about 5 roentgens, most of the exposure being limited to the mouth of the patient.

\section{$X$-ray in Indusfry}

Industrial X-ray devices include primarily (a) radiographic and fluoroscopic units used for the determination of defects in castings, fabricated structures, and welds, and $(b)$ fluo- roscopic units used for the detection of foreign material in, for example, packaged foods. At present, there are approximately 800 industrial radiographic installations in the United States (3), and about 5,000 persons are potentially exposed to radiation in the use of the equipment. Industrial X-ray units, both radiographic and fluoroscopic, probably number about 2,000 .

Exposure levels for personnel operating these machines depend upon the type of installation and the operating procedures used. Most permanent installations were designed and the personnel assignments planned so as to limit exposures to the levels recommended by the National Committee on Radiation Protection at the time the installation was built. However, the downward revision of the maximum permissible dose calls for a reevaluation of the older installations.

Fluoroscopy is also sometimes used for the scanning of personnel to detect pilfering. Exposures of 0.045 to 0.09 roentgen per inspection may be received by the "subject." The unit operator may receive 0.1 roentgen, largely limited to his head and shoulders, for each 50 persons inspected (4).

Other potential sources of $\mathrm{X}$-ray exposure in industry are found in connection with the manufacture, testing, and operation of highvoltage electronic tubes. Personnel exposures may range as high as 2.5 roentgens per day.

\section{Commercial Use of X-ray}

The use of fluoroscopy in shoe-fitting results in radiation exposures to both operators of the fluoroscopes and the public. Mean exposures for the customer range from 7 to 14 roentgens per 20 -second exposure. Although the radiation is intended only for the feet, dosages of 0.03 to 0.17 roentgen per 20 -second exposure may be received by the pelvis. The number of exposures received by shoe customers is not known. In the operation of the approximately 10,000 fluoroscopes in the United States, 30,000 to 40,000 sales people are exposed to radiation.

\section{$X$-ray in Research}

With the development of atomic and nuclear physics, high-voltage $\mathrm{X}$-ray machines have be- 
come familiar features of research laboratories in universities and similar institutions. Few data are available as to the levels of exposure received by personnel in these radiation laboratories. Injuries have probably been held to a minimum by frequent turnover of personnel. However, in laboratories where cyclotrons, linear accelerators, and positive ion tubes, as well as high-voltage $\mathbf{X}$-ray machines, are used, it is estimated that there is a frequency rate of "one palpable injury per 20 to 30 man-years of active employment in radiation work" (5).

Also in use for research purposes are about $1,500 \mathrm{X}$-ray diffraction units. Surveys of these units by the radiological health branch of the Public Health Service have recorded intensities of scattered radiation up to 1 roentgen per hour. Several cases of skin ulcers resulting from accidental overexposures in the use of these units have been reported.

Another X-ray unit found in many laboratories is the electron microscope. Approximately 500 are in use. Intensities of scattered radiation from these units may range up to $\mathbf{1 . 5}$ roentgens per hour.

\section{Radioisotopes Distributed by AEC}

More than 900 universities, hospitals, and research laboratories in 46 States have used or are using radioisotopes produced by the Atomic Energy Commission for medical, biological, industrial, agricultural, and scientific research, and medical diagnosis and treatment. During 1950 an average of 45 curies of radioactive isotopes were distributed per month. There are currently some 7,500 persons who are directly involved in the use of these materials. About 1 in 300 radioisotope users exceeds the present-day maximum permissible dose in a given week. Fifty to seventy-five percent receive less than 0.05 roentgen per week.

Patients to whom radioisotopes are administered internally may receive up to 10 or more roentgens whole-body exposure from diagnostic doses and 75 to 100 roentgens from therapeutic doses. Calculated dosages to single organs, such as the thyroid gland, range from 10,000 to 300,000 roentgens.

Radioisotopes are also used in medical therapy as external sources of radiation. Beta-ray applicators are available for the treatment of certain eye conditions. Cobalt-60 is available in the form of large shielded concentrated sources for deep therapy and in the form of small needle sources for intracavitary and interstitial therapy.

Cobalt-60 is used industrially for radiography. About 80 sources are being used in the United States in industries such as railroading, steel production, boiler-making, automobile manufacture, ceramics production, pressure vessel manufacture, and the making of castings. The intensity of radiation from 1 curie of unshielded cobalt-60 at 1-foot distance is 14.4 roentgens per hour. The quantities used in industry range from 100 or 200 millicuries up to as high perhaps as 1 curie.

Thickness gauges using radioisotopes are becoming more and more popular in industry. More than 50 such gauges using strontium-90 and some 20 using other radioisotopes are presently in use in the United States. Surveys have shown that the external radiation to which personnel working around these units are exposed is well below the maximum permissible dose. Strontium-90 is also used to activate phosphors for use in luminous markers, which are hermatically sealed to prevent escape of the radioactive material.

These and other radioisotopes are being widely used in a variety of industrial research problems.

Within the next few years, industrial uses of fission products are expected to become more widespread. Through 1950, however, only about 4 curies had been distributed by the Atomic Energy Commission.

Wastes from the use of radioisotopes in industry, the medical profession, and research laboratories could cause radiation exposure to persons outside the installations using the radioisotopes. Safe disposition procedures are well covered in official publications.

\section{Radium}

The radiation from 1 curie of radium, in equilibrium with its decay products and enclosed in $0.5 \mathrm{~mm}$. of platinum will produce a gamma-ray exposure of about 9.0 roentgens per hour at a distance of 1 foot. 


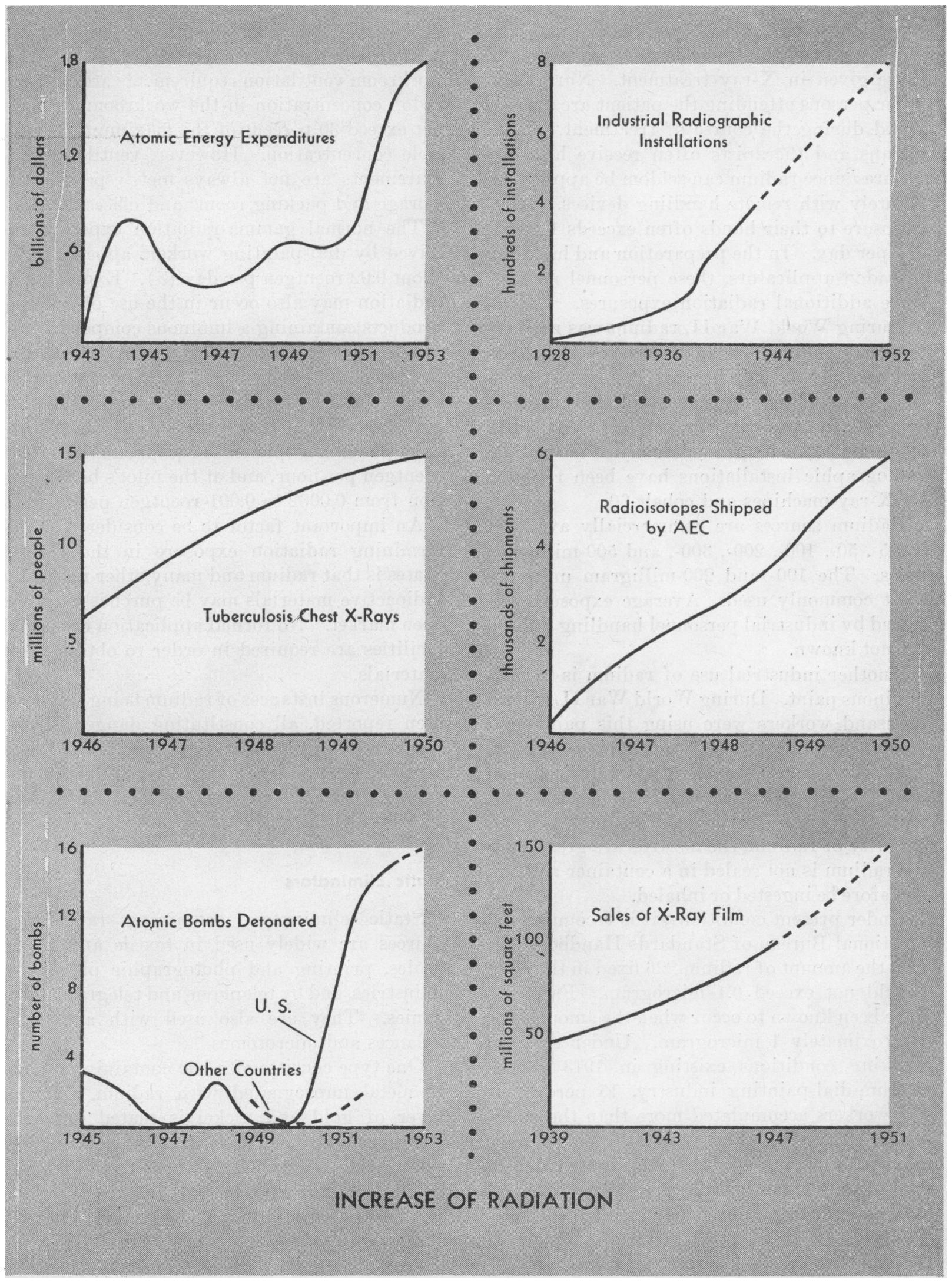

Vol. 68, No. 1, January 1953 
Many individuals are potentially exposed to radiation in the medical use of radium. $\mathbf{P a}$ tients receive radiation dosages comparable to those given in X-ray treatment. Nurses and other persons attending the patient are also exposed during the course of treatment. Technicians and therapists often receive high exposures since radium can seldom be applied accurately with remote handling devices. Local exposure to their hands often exceeds 1 roentgen per day. In the preparation and handling of radon applicators, these personnel may receive additional radiation exposures.

During World War II, radium was used extensively in the United States for industrial radiography, largely because $X$-ray units were difficult to obtain. As much as $\mathbf{1 0 0}$ grams were in use. In 1948, the amount had declined to 50 grams (6). At present, many of the radium radiographic installations have been replaced by $\mathrm{X}$-ray machines and cobalt- 60 .

Radium sources are commercially available in 25-, 50-, 100-, 200-, 300-, and 500-milligram units. The 100- and 200-milligram units are most commonly used. Average exposures received by industrial personnel handling radium are not known.

Another industrial use of radium is in selfluminous paint. During World War II, several thousand workers were using this paint, and several hundred grams of radium were utilized. After the war, the number of workers decreased until in 1948 there were only about 300 (6). Although each worker handles only a small quantity of radium, the hazards are great since the radium is not sealed in a container and can therefore be ingested or inhaled.

Under present conditions, it is recommended (National Bureau of Standards Handbook 47) that the amount of radium-226 fixed in the body should not exceed 0.1 microgram. Fatalities have been known to occur when the amount was approximately 1 microgram. Under the best working conditions existing in 1943 in the radium-dial-painting industry, 15 percent of the workers accumulated more than the maximum permissible amount (7). In a recently reported survey at an instrument shop, a degree of radium contamination greatly in excess of the maximum permissible concentration was found.
It is generally accepted that the maximum permissible concentration for radon in the air is 10 micromicrocuries per liter (5). When workroom ventilation requirements are met, the radon concentration in the workroom air does not exceed 30 percent of the maximum permissible concentration. However, ventilation requirements are not always met, especially in storage and packing rooms and offices.

The normal gamma-radiation exposure received by dial-painting workers appears to be about 0.02 roentgen per day (5). Exposures to radiation may also occur in the use of finished products containing a luminous compound. A watch may have approximately 1 microgram of radium on it. Some clocks and aircraft instruments contain from 10 to 100 micrograms of radium. The level of exposure at the instrument panel in airplanes so equipped may be 0.01 roentgen per hour, and at the pilot's body position from 0.0002 to 0.001 roentgen per hour.

An important factor to be considered in determining radiation exposure in the United States is that radium and many other naturally radioactive materials may be purchased on the open market. No formal application or special facilities are required in order to obtain these materials.

Numerous instances of radium being lost have been reported, all constituting danger of unsuspected radiation exposure. Taft $(8)$ has reported on 107 losses, with 59 complete recoveries, 11 partial recoveries, 36 total losses, and 1 not recorded.

\section{Static Eliminators}

Static eliminators containing radioactive sources are widely used in textile and paper trades, printing and photographic processing industries, and by telephone and telegraph companies. They are also used with analytical balances and microtomes.

One type consists of a bar containing a strip of metal impregnated with radium. A thin layer of gold and nickel is plated over the radium metal strip to protect the radium and act as a seal. The main hazards from this type result from exposure to beta and gamma radiation (alpha constitutes little external hazard) and radon gas. 
Exposure levels in the working areas near these units are generally about 0.005 roentgen per hour but may range up to 0.085 roentgen per hour. Unless care is exercised and the necessary shields used, maintenance men and other workers whose duties require them to be close to such units frequently can be exposed to radiation levels as high as 1 roentgen per hour.

The radon hazard is small if the units are given proper care and used in ventilated areas. However, if the seal is broken, a radon hazard may result. Several surveys have pointed out that improper storage and handling of static eliminators is common.

A second type of static eliminator contains polonium as the radioactive source. This unit constitutes little external radiation hazard since the alpha particles from polonium travel only a short distance in air. The hazards associated with its use result from ingesting, absorbing, or inhaling polonium liberated through breaking or flaking of the gold seal.

Small polonium bars are also mounted on brushes as static charge eliminators for phonograph records and photographic films.

A point about polonium that must be given careful consideration in certain applications is that polonium volatilizes at lower temperatures than radium.

\section{Shipping of Radioactive Materials}

Radiation exposures can occur during the handling and shipping of radioactive materials. Under the current regulations governing the shipment of these materials by air, the maximum exposure which an airplane crew member or passenger could receive would be 0.012 roentgen per hour. The maximum exposure for pilots (flying 85 hours per month) would therefore be 1.02 roentgens per month (9).

\section{Nuclear Reactors}

Radiation exposures associated with the operation of nuclear reactors include those from the reactor itself, from its ventilation and cooling effluents, and from its fission products.

Data on the "water boiler" type reactor being built at the North Carolina State College serves as a tentative guide in establishing the

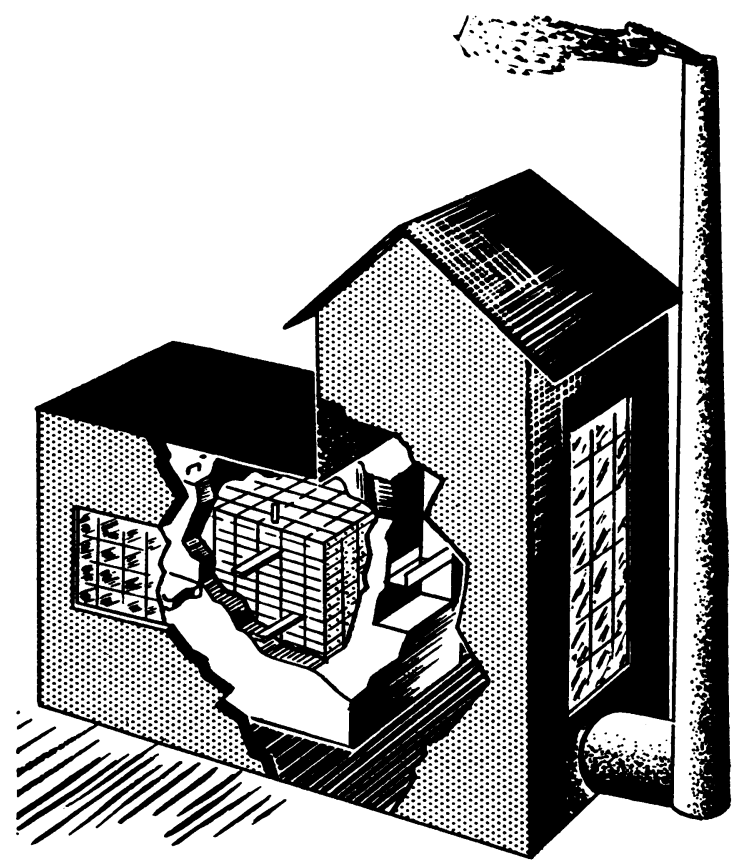

Enriched-uranium, graphite-moderated reactor

importance of such installations as sources of radiation exposure (10).

A maximum of some $10^{5}$ curies of activity will be present in the fuel solution of this reactor. Heavy shielding will be required to limit all radiation exposure from the reactor and its accessories to a safe level.

At maximum operating level, 10 kilowatts, the reactor will require 3 gallons of water per minute for cooling. Upon leaving the reactor, the water will contain some 1,000 disintegrations per second per cubic centimeter. Assuming no shielding and no internal absorption of radiation by the water, 10 gallons of freshly irradiated water would produce a radiation dosage rate of approximately 0.08 roentgen per 8 hours at a distance of 5 feet. After 1 hour, the dosage rate would drop to about 0.0008 roentgen per 8 hours at a distance of 5 feet. Tanks for collecting and retaining this waste water for 10 hours will be provided.

Some 40 liters per hour of waste gases will be produced at 5 kilowatts normal operating level. The activity of these gases will amount initially to about 7,000 curies per kilowatt minute. After 4 hours, however, this 7,000 curies will have decayed to 0.15 curie.

Solid as well as other liquid and gaseous wastes will result if laboratory or experimental 
programs are conducted in conjunction with operation of the reactor, or if the used nuclear fuels are reprocessed.

A second type of nuclear reactor, an enriched-uranium, graphite-moderated reactor, is being built for industrial research. It will be operated at a maximum power level of 200 kilowatts. Shielding, weighing a total of 450 tons, will be provided by 6 inches of steel and about 3 feet of "heavy" concrete. Data as to the wastes from operation of this reactor and the possible resulting radiation exposures have not been released.

Undoubtedly, other reactors will soon be built at other colleges and universities and in industry. At least five major universities have expressed interest in following the steps of North Carolina State College.

\section{Particle Accelerators}

In 1941 , there were only some 16 cyclotron laboratories in the United States. Today, however, more than 100 particle accelerator units, including cyclotrons, synchrotrons, van de -Graaff generators, and betatrons, are in use.

Exact determination of the type and intensity of radiation encountered around particle accelerators is often difficult and sometimes impossible because of the mixture of radiations present. Beta radiation originates from the various accelerators, but the possibility of direct exposure is slight. Neutrons probably constitute one of the main hazards, as they are produced in profusion in the operation of cyclotrons and synchrotrons.

Impaired vision of several nuclear physicists as a result of work with cyclotrons was reported

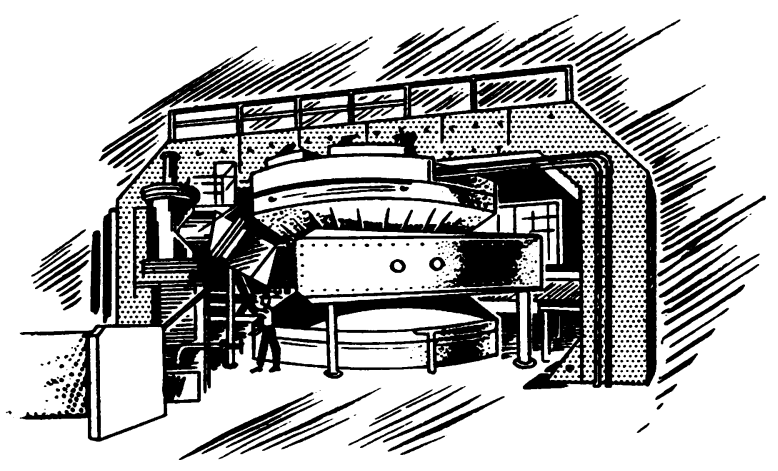

The 184-inch Berkeley synchrocyclotron recently. The general injury rate for laboratory radiation workers was discussed above under X-ray in Research.

\section{AEC Activities}

Activities sponsored by the Atomic Energy Commission which result in radiation exposure include uranium mining and milling, nuclear reactor operations, and testing of weapons.

Uranium mining and milling in this country is carried on primarily in the region of the Colorado Plateau. Some 2,000 miners and millers are engaged in this work. The mining and processing of the ores and metals yields dusts and fumes which are sources of radioactive air pollutants. Radon gas is also a hazard. The Public Health Service and several State health agencies, which are active in studies of the specific hazards in this industry, have reported finding radon exposures above the maximum permissible concentration in several of the mines. In these instances, control measures, particularly ventilation, are being applied as rapidly as possible. Detailed physical examinations of over 1,100 workers have revealed no evidence of health damage from radioactivity.

Atomic Energy Commission installations conducting nuclear reactor operations are located in many areas of the United States. The radius of the potential health hazards of these operations may be increased by the discharge of radioactive liquid and gaseous wastes. For example, the installation at Oak Ridge, Tenn., discharges up to 5 curies per day of liquid wastes to the White Oak Creek. The potential risks are by no means always confined to those directly associated with such activities. For these reasons, an effective radiation control program has been an integral part of atomic energy operations since their inception.

In 1951, 12 bombs were detonated at the AEC Proving Ground in Nevada. The activity 1 hour after detonation of a nominal atomic bomb is approximately $10^{\circ}$ curies. One week later, about $10^{7}$ curies remain. Fortunately the majority of this radiation probably remains in the upper atmosphere, but some of it is widely distributed causing a temporary average increase in radioactivity throughout the United States. 


\section{Accidents}

Numerous instances of radiation injury from accidents have been recorded in the literature. Moreover, it is believed that these represent only a small fraction of the accidents which occur. Any radiation exposure resulting from accidents would be in addition to the exposures discussed here. Obviously, the potential amount of exposure and the probable severity of injury incurred in an accident would vary with the amount of radiation involved.

\section{Summary and Conclusions}

A review of the literature reveals that the average annual radiation exposure from medical diagnostic procedures is about 2 roentgens per person. This exposure is received by a large portion of the population. Other medical sources of exposure are dental X-rays and medical radiation treatments.

Many segments of the population receive additional exposures as a result of contact with radioactive materials and radiation-generating units in commerce, industry, and research.

From the data presented, it is not possible to reach definitive conclusions as to the magnitude of the radiological health problem or as to the relative importance to public health of the several sources of ionizing radiation. It is hoped, however, that publication of this paper will encourage further studies which will lead to more conclusive data.

This review, meanwhile, indicates that large numbers of the population are currently exposed to radiation appreciably in excess of natural background. Such exposure often approaches doses recommended as the maximum permissible for radiation workers. The sources of these exposures vary from community to community, and their relative health importance is continually changing.

A tremendous national effort is being made by military and civilian agencies to expand the production and use of radioactive materials. It is expected that the near future will bring nuclear reactors for power production, research, and transportation into widespread use. Many radiological health workers believe that as this technological development occurs pro- tection from radiation must become a major concern of public health programs. The time to organize and train to meet the radiological health responsibility of the future is at hand. The ability of health workers to cope with public health problems arising from the increasing hazard of ionizing radiation will be more readily developed if they learn to search out and to deal with the radiological health problems of today.

\section{REFERENCES}

(1) Donaldson, S. W.: Practice of radiology in the United States; facts and figures. Am. J. Roentgenol. 66: 929 (1951).

(2) Spalding, Charles K., DeAmicis, Egilda, and Cowing, Russell F.: Radiation-exposure survey of $\mathrm{X}$-ray and isotope personnel. Nucleonics 5: 63-66 (December 1949).

(\$) Isenburger, Herhert R. : Personal communication.

(4) Soet, John C.: Radiation protection from the industrial hygiene standpoint. Indust. Med. Surg. 20: 227-233 (1951).

(5) Parker, H. M.: Health-physics, instrumentation, and radiation protection. In Advances in biological and medical physics, edited by John $\mathbf{H}$. Lawrence and Joseph G. Hamilton. New York, Academic Press, Inc., 1948, vol. I, pp. 223-285.

(6) Williams, Charles R.: Radiation hazards in industry. J. Indust. Hyg. \& Toxicol. 30: 294299 (1948).

(7) Evans, Robley D.: Protection of radium dial workers and radiologists from injury by radium. J. Indust. Hyg. \& Toxicol. 25: 253269 (1943).

(8) Taft, R. H. : Radium lost and found. Charleston, S. C., John J. Furlong and Son, Inc., 1938.

(9) Evans, R. D.: Physical, biological, administrative problems associated with the transportation of radioactive substances. Preliminary report No. 11. Nuclear Science Series No. 205. Washington, D. C., National Research Council, 1950.

(10) Beck, Clifford K., Menius, Arthur C., Webb, George N., Walter, Arthur W., Leonard, P. B. Stinson, E. H., and Paulson, J. D.: Program administration and installation design of the nuclear reactor project at North Carolina State College. Publication No. ORO-33. Oak Ridge, Tenn., U. S. Atomic Energy Commission, July 5, 1950.

A complete bibliography of the source material for this article is available from the radiological health branch, Division of Engineering Resources, Bureau of State Services, Public Health Service. 